\title{
OPTIMALISASI PENDISTRIBUSIAN BERAS DI PENGGILINGAN PADI KARDI JAYA UTAMA TOLAI DENGAN MENGGUNAKAN METODE GOAL PROGRAMMING
}

\author{
R. Fatmayoni ${ }^{1}$, A. I. Jaya ${ }^{2}$, dan Resnawati ${ }^{3}$ \\ 1,2,3 Program Studi Matematika Jurusan Matematika FMIPA Universitas Tadulako \\ Jalan Soekarno-Hatta Km. 09 Tondo, Palu 94118, Indonesia. \\ 1raisan1992.rf@gmail.com, 2jayaindraagus@gmail.com, 3r35n4w4t1@yahoo.com
}

\begin{abstract}
Rice Milling Tolai Kardi Jaya Utama is a company that serves the demand of rice for the agents. In addition to maximizing inventory, Rice Milling should also maximize the use of public transport for the distribution of rice and minimize distribution costs per month based on the price of fuel, driver wages, labor costs and the cost of repairing or servicing the truck. Goal Programming method is a method that can resolve the issue by more than one goal. Goal Programming model formulation in this study consisted of 6 priority and 6 function constraints. These priorities is the capacity of the warehouse in accordance with the supply of rice, the target number of trucks used for rice distribution in Parigi Moutong, Palu, Manado, Poso, and distribution cost targets to be achieved. Constraint functions consisting of rice in the warehouse inventory Rice Milling Kardi Jaya Utama, the number of trucks for the distribution of rice in Parigi Moutong, Palu, Manado, Poso, and distribution costs. Results showed a maximum supply of rice based warehouse capacity can meet the six-month distribution of rice in the region Moutong Parigi, Palu, Manado, and Poso in the amount of 8.76189 million kg. In order for optimal distribution of rice in Parigi Moutong then require 80 times the distribution uses one unit of a truck with a capacity of 5 tons, 90 times using three trucks 5 tons to Palu, 20 times using three trucks 15 tons to Manado, and 33 times the distribution using 2 units trucks with a capacity of 10 tons to the Poso region. Goal Programming method can save distribution costs Rp. 35.34894 million or $10.76 \%$ of the distribution costs for the year 2014 issued by the Rice Milling Kardi Jaya Utama Tolai, which amounted to Rp. 328560500.
\end{abstract}

Keywords $\quad$ : Cost Distribution, Goal Programming, Rice Stocks, Trucks.

\section{ABSTRAK}

Penggilingan Padi Kardi Jaya Utama Tolai adalah perusahaan yang melayani permintaan beras bagi para agen. Selain memaksimalkan persediaan, Penggilingan Padi juga harus memaksimalkan penggunaan angkutan untuk pendistribusian beras serta meminimumkan biaya pendistribusian per bulan berdasarkan harga BBM, upah sopir, upah buruh dan biaya perbaikan atau servis pada truk. Metode Goal Programming merupakan metode yang dapat menyelesaikan persoalan dengan tujuan lebih dari satu. Formulasi model Goal Programming pada penelitian ini terdiri dari 6 prioritas dan 6 fungsi kendala. Prioritas-prioritas tersebut adalah kapasitas gudang 
sesuai dengan persediaan beras, target jumlah truk yang digunakan untuk distribusi beras di Parigi Moutong, Palu, Manado, Poso, dan target biaya distribusi yang ingin dicapai. Fungsi kendala terdiri atas persediaan beras di gudang Penggilingan Padi Kardi Jaya Utama, banyaknya truk untuk pendistribusian beras di Parigi Moutong, Palu, Manado, Poso, dan biaya distribusi. Hasil penelitian menunjukkan persediaan maksimal beras berdasarkan kapasitas gudang dapat memenuhi 6 bulan penyaluran beras di wilayah Parigi Moutong, Palu, Manado, dan Poso yaitu sebesar $8.761 .890 \mathrm{~kg}$. Agar pendistribusian beras dapat optimal di Parigi Moutong maka membutuhkan 80 kali pendistribusian menggunakan 1 unit truk berkapasitas 5 ton, 90 kali menggunakan 3 unit truk 5 ton ke Palu, 20 kali menggunakan 3 unit truk 15 ton ke Manado, dan 33 kali distribusi menggunakan 2 unit truk berkapasitas 10 ton ke wilayah Poso. Metode Goal Programming ini dapat menghemat biaya pendistribusian sebesar Rp. 35.348.940 atau 10,76\% dari biaya distribusi selama tahun 2014 yang dikeluarkan oleh Penggilingan Padi Kardi Jaya Utama Tolai, yakni sebesar Rp. 328.560.500.

Kata Kunci $\quad$ : Biaya Distribusi, Goal Programming, Persedian Beras, Truk.

\section{PENDAHULUAN}

\subsection{Latar Belakang}

Beras merupakan bahan makanan utama masyarakat Indonesia. Beras dimanfaatkan terutama untuk diolah menjadi nasi, dan berbagai varias makanan lain. Semua orang membutuhkan beras, karena produk ini menjadi makanan pokok masyarakat khususnya warga Indonesia. Dari mulai anak kecil, remaja, sampai orang tua membutuhkan beras sebagai bahan makanan utama sehari-hari (Wikipedia, 2014). Penggilingan padi Kardi Jaya Utama Tolai adalah perusahaan yang melayani permintaan beras bagi para agen. Layanan pendistribusian beras untuk para toko dibatasi oleh permintaan dari masing-masing toko tersebut. Dalam hal pendistribusian untuk pengalokasian beras ke beberapa toko tujuan, hal meminimumkan total biaya transportasi masih menjadi masalah bagi perusahaan.

Optimalisasi kinerja, penggilingan padi menambahkan faktor-faktor seperti minimalisasi biaya, jumlah truk yang digunakan agar dapat mengoptimalkan kapasitas angkut beras kepada toko-toko, serta memaksimalkan keuntungan dari penggilingan padi itu sendiri. Usaha pencapaian tujuan yang beragam, membutuhkan suatu metode analisis yang menghasilkan optimalisasi tujuan-tujuan tersebut. Salah satu diantaranya adalah metode Goal Pragramming.

Goal Programming merupakan perluasan dari Linear Programming untuk mencapai tujuan atau target yang diinginkan. Aplikasi Goal Pragramming pertamanya dilakukan oleh Charnes dan Cooper pada tahun 1961. Charnes dan Cooper mengembangkan pendekatan program tujuan untuk memperoleh solusi yang memuaskan, yang tidak bisa diperoleh dengan 
pendekatan Linear Programming karena adanya konflik atau penyimpangan antar tujuan. Analisis Goal Programming bertujuan untuk meminimumkan jarak antara atau deviasi terhadap tujuan, target atau sasaran yang telah ditetapkan dengan usaha yang dapat ditempuh. Untuk mencapai target atau tujuan tersebut secara optimal harus sesuai dengan syarat yang membatasinya berupa sumber daya yang tersedia, teknologi yang ada, kendala tujuan, dan sebagainya (Vinsensia. D, 2009).

\subsection{Rumusan Masalah}

Berdasarkan latar belakang masalah yang telah di uraikan di atas, maka permasalahan dari penelitian ini adalah:

1. Berapa persediaan maksimal beras tiap bulannya sesuai dengan kapasitas gudang?

2. Berapa biaya minimal pendistribusian beras per bulan berdasarkan harga BBM, upah supir, upah buruh dan biaya perbaikan atau servis pada truk?

3. Berapa jumlah truk yang digunakan agar kegiatan penyaluran beras ke wilayah Kabupaten Parigi Moutong, Kota Palu, Kota Manado dan Kota Poso dapat optimal menggunakan Goal Programming?

\subsection{Tujuan}

Adapun tujuan yang ingin dicapai dalam penelitian ini adalah:

1. Mendapatkan persediaan beras per bulan sesuai dengan kapasitas gudang

2. Mendapatkan biaya pendistribusian beras per bulan berdasarkan harga BBM, upah sopir, upah buruh dan biaya perbaikan atau servis pada truk.

3. Mendapatkan jumlah truk yang digunakan untuk kegiatan penyaluran beras ke wilayah Kabupaten Parigi Moutong, Kota Palu, Kota Manado dan Kota Poso dapat optimal melalui metode Goal Programming.

\subsection{Batasan Penelitian}

Adapun batasan masalah dalam penelitian ini yaitu:

1. Wilayah yang menjadi jangkauan pendistribusian beras adalah Kabupaten Parigi Moutong, Kota Palu, Kota Manado dan Kota Poso.

2. Persediaan beras, jumlah truk, dan biaya distribusi yang diteliti berdasarkan harga BBM, upah sopir, upah buruh dan biaya perbaikan atau servis pada truk yang berasal dari Penggilingan Padi Kardi Jaya Utama Tolai.

3. Harga BBM yang digunakan yaitu harga pada bulan Desember 2014.

4. Kondisi jalan dan waktu pendistribusi diabaikan. 


\section{METODE PENELITIAN}

Berikut adalah prosedur penelitian yang akan dilakukan:

1. Mulai penelitian

2. Studi literatur dilakukan dengan mengumpulkan materi dari buku, artikel, dan jurnal.

3. Pengambilan data

4. Membangun model matematika dari data yang diperoleh

5. Menyelesaikan model matematika tersebut menggunakan metode Goal Programming.

6. Menyimpulkan hasil penelitian

7. Selesai.

III. HASIL DAN PEMBAHASAN

\subsection{Pengumpulan data}

Adapun data yang diperoleh yaitu:

1. Kapasitas gudang Penggilingan Padi Kardi Jaya Utama Tolai

Kapasitas gedung Penggilingan Padi Kardi Jaya Utama Tolai yaitu sebesar 10.000.000 kg dengan ukuran $30 \mathrm{~m} \times 20 \mathrm{~m} \times 4 \mathrm{~m}$.

2. Permintaan dan persediaan beras tahun 2014

Tabel 1 : Permintaan dan Persediaan Beras Tahun 2014

\begin{tabular}{|c|c|c|}
\hline Nama Daerah & $\begin{array}{c}\text { Permintaan / Bulan } \\
(\mathrm{Kg})\end{array}$ & Persediaan / 3 Bulan (Kg) \\
\hline Parigi Moutong & 400.095 & 1.200 .000 \\
\hline Palu & 450.085 & 1.350 .000 \\
\hline Manado & 290.060 & 870.000 \\
\hline Poso & 320.075 & 960.000 \\
\hline Total & 1.460 .315 & 4.380 .000 \\
\hline
\end{tabular}

Sumber: Penggilingan Padi Kardi Jaya Utama Tolai

3. Biaya Pendistribusian Beras

Dalam melakukan pendistribusian beras dari gudang ke masing-masing daerah, Penggilingan Padi Kardi Jaya Utama Tolai menggunakan truk bermuatan 5 ton, 10 ton, atau 15 tondengan hitungan biaya antara lain:
a. Upah Buruh
$: R p \cdot \frac{12.500}{\text { Ton }}$ atau $R p \cdot \frac{12,5}{K g}$
b. Harga BBM
:Rp.6.200/L (Solar)
c. Asumsi Jumlah BBM perliter : $1 \mathrm{~L} / 12 \mathrm{~km}$ 
Tabel 2

: Biaya Pendistribusian beras

\begin{tabular}{|l|c|}
\hline \multicolumn{1}{|c|}{ Nama Daerah } & $\begin{array}{c}\text { Biaya Pendistribusian } \\
\text { Beras (Rp) }\end{array}$ \\
\hline Parigi Moutong & 62.935 .364 \\
\hline Palu & 88.673 .434 \\
\hline Manado & 97.180 .675 \\
\hline Poso & 79.771 .027 \\
\hline \multicolumn{1}{|c|}{ Total } & 328.560 .500 \\
\hline
\end{tabular}

Sumber: Penggilingan Padi Kardi Jaya Utama Tolai

4. Harga upah supir, buruh, harga BBM dan biaya servis truk pengangkut beras

Tabel 3 : Biaya BBM yang Dibutuhkan Per Truk

\begin{tabular}{|c|c|c|c|c|}
\hline Nama Daerah & $\begin{array}{c}\text { Jarak } \\
\text { Terpendek } \\
(\mathrm{km})\end{array}$ & $\begin{array}{c}\text { Jumlah Solar } \\
(\mathrm{L})\end{array}$ & Harga (Rp) & Total (dikali 2) \\
\hline $\begin{array}{c}\text { Parigi } \\
\text { Moutong }\end{array}$ & 35 & 2,92 & 6.200 & 36.208 \\
\hline Palu & 130 & 10,83 & 6.200 & 134.292 \\
\hline Manado & 1000 & 83,33 & 6.200 & 1.033 .292 \\
\hline Poso & 108 & 9 & 6.200 & 111.600 \\
\hline
\end{tabular}

Tabel $4 \quad$ : Truk Kapasitas 5 Ton

\begin{tabular}{|c|c|c|c|c|c|}
\hline Nama Daerah & $\begin{array}{c}\text { Upah Supir } \\
\text { Per truk (Rp) }\end{array}$ & $\begin{array}{c}\text { Upah Buruh } \\
\text { Per Truk (Rp) }\end{array}$ & $\begin{array}{c}\text { Biaya Bahan } \\
\text { Bakar per Truk } \\
(\mathrm{Rp})\end{array}$ & $\begin{array}{c}\text { Biaya servis } \\
\text { Per Bulan } \\
(\mathrm{Rp})\end{array}$ & Total (Rp) \\
\hline Parigi Moutong & 50.000 & 62.500 & 36.208 & 540.000 & 688.708 \\
\hline Palu & 85.000 & 62.500 & 134.292 & 690.000 & 971.792 \\
\hline Manado & 150.000 & 62.500 & 1.033 .292 & 890.000 & 2.085 .792 \\
\hline Poso & 70.000 & 62.500 & 111.600 & 625.900 & 870.000 \\
\hline
\end{tabular}

Sumber:Penggilingan Padi Kardi Jaya Utama Tolai

Tabel 5 : Truk Kapasitas 10 Ton

\begin{tabular}{|c|c|c|c|c|c|}
\hline Nama Daerah & $\begin{array}{c}\text { Upah Supir } \\
\text { Per truk (Rp) }\end{array}$ & $\begin{array}{l}\text { Upah Buruh } \\
\text { Per Truk (Rp) }\end{array}$ & $\begin{array}{c}\text { Biaya Bahan } \\
\text { Bakar per Truk } \\
\text { (Rp) }\end{array}$ & $\begin{array}{c}\text { Biaya servis } \\
\text { Per Bulan } \\
\text { (Rp) }\end{array}$ & Total (Rp) \\
\hline Parigi Moutong & 100.000 & 125.000 & 36.208 & 1.395 .000 & 1.656 .208 \\
\hline Palu & 170.000 & 125.000 & 134.292 & 1.740 .000 & 2.169.292 \\
\hline Manado & 200.000 & 125.000 & 1.033 .292 & 1.845 .000 & 3.203.292 \\
\hline Poso & 140,000 & 125.000 & 111.600 & 1.570 .000 & 1.946 .600 \\
\hline
\end{tabular}

Sumber:Penggilingan Padi Kardi Jaya Utama Tolai 
Tabel 6 : Truk Kapasitas 15 Ton

\begin{tabular}{|c|c|c|c|c|c|}
\hline $\begin{array}{c}\text { Nama } \\
\text { Daerah }\end{array}$ & $\begin{array}{c}\text { Upah Supir } \\
\text { Per truk } \\
(\mathrm{Rp})\end{array}$ & $\begin{array}{c}\text { Upah Buruh } \\
\text { Per Truk } \\
(\mathrm{Rp})\end{array}$ & $\begin{array}{c}\text { Biaya Bahan } \\
\text { Bakar per Truk } \\
(\mathrm{Rp})\end{array}$ & $\begin{array}{c}\text { Biaya servis } \\
\text { Per Bulan } \\
(\mathrm{Rp})\end{array}$ & Total (Rp) \\
\hline Parigi Moutong & 200.000 & 187.500 & 36.208 & 2.105 .000 & 2.528 .708 \\
\hline Palu & 270.000 & 187.500 & 134.292 & 2.790 .000 & 3.381 .792 \\
\hline Manado & 300.000 & 187.500 & 1.033 .292 & 2.800 .000 & 4.320 .792 \\
\hline Poso & 240,000 & 187.500 & 111.600 & 2.525 .000 & 3.064 .100 \\
\hline
\end{tabular}

Sumber:Penggilingan Padi Kardi Jaya Utama Tolai

\subsection{Penentuan Variabel Keputusan}

Variabel keputusan dinyatakan dengan:

$X_{1}=$ Persediaan beras di gudang

$X_{2}=$ Banyaknya truk pengangkut beras untuk Kabupaten Parigi Moutong

$X_{3}=$ Banyaknya truk pengangkut beras untuk Kota Palu

$X_{4}=$ Banyaknya truk pengangkut beras untuk Kota Manado

$X_{5}=$ Banyaknya truk pengangkut beras untuk Kota Poso

\subsection{Fungsi Tujuan dan Kendala Tujuan}

Setelah menentukan prioritas dan urutannya, fungsi tujuan yang terbentuk adalah:

Minimumkan $\mathrm{Z}=P_{1}\left(d_{1}{ }^{+}+{d_{1}}^{-}\right)+P_{2}\left(d_{2}{ }^{+}+{d_{2}}^{-}\right)+P_{3}\left(d_{3}{ }^{+}+{d_{3}}^{-}\right)+P_{4}\left(d_{4}{ }^{+}+{d_{4}}^{-}\right)+P_{5}\left(d_{5}{ }^{+}+\right.$

$$
\left.d_{5}{ }^{-}\right)+P_{6}\left(d_{6}{ }^{+}+d_{6}{ }^{-}\right)
$$

Kendala tujuan:

1. Kendala tujuan 1 (truk berkapasitas muatan 5 ton):

$$
\begin{aligned}
1.460 .315 X_{1}+d_{1}{ }^{-}-d_{1}{ }^{+} & =10.000 .000 \mathrm{~kg} \\
5.000 X_{2}+d_{2}{ }^{-}-d_{2}{ }^{+} & =400.095 \mathrm{~kg} \\
5.000 X_{3}+d_{3}{ }^{-}-d_{3}{ }^{+} & =450.085 \mathrm{~kg} \\
5.000 X_{4}+d_{4}{ }^{-}-d_{4}{ }^{+} & =290.060 \mathrm{~kg} \\
5.000 X_{5}+d_{5}{ }^{-}-d_{5}{ }^{+} & =320.075 \mathrm{~kg}
\end{aligned}
$$

$R p .688 .708 X_{6}+R p .971 .792 X_{7}+R p \cdot 2.085 .792 X_{8}+$

$R p .870 .000 X_{9}+d_{6}{ }^{-}-d_{6}{ }^{+}=R p .328 .560 .500$

2. Kendala tujuan 2 (truk berkapasitas muatan 10 ton)

$$
\begin{aligned}
1.460 .315 X_{1}+d_{1}{ }^{-}-d_{1}{ }^{+} & =10.000 .000 \mathrm{~kg} \\
10.000 X_{2}+d_{2}{ }^{-}-d_{2}{ }^{+} & =400.095 \mathrm{~kg} \\
10.000 X_{3}+d_{3}{ }^{-}-d_{3}{ }^{+} & =450.085 \mathrm{~kg} \\
10.000 X_{4}+d_{4}{ }^{-}-d_{4}{ }^{+} & =290.060 \mathrm{~kg} \\
10.000 X_{5}+d_{5}{ }^{-}-d_{5}{ }^{+} & =320.075 \mathrm{~kg}
\end{aligned}
$$

$R p .1 .656 .208 X_{6}+R p .2 .169 .292 X_{7}+R p .3 .203 .292 X_{8}+$

$R p .1 .946 .600 X_{9}+d_{6}{ }^{-}-d_{6}{ }^{+}=R p .328 .560 .500$ 
3. Kendala tujuan 2 (truk berkapasitas muatan 15 ton)

$$
\left.\begin{array}{c}
1.460 .315 X_{1}+d_{1}{ }^{-}-d_{1}{ }^{+}=10.000 .000 \mathrm{~kg} \\
15.000 X_{2}+d_{2}{ }^{-}-d_{2}{ }^{+}=400.095 \mathrm{~kg} \\
15.000 X_{3}+d_{3}{ }^{-}-d_{3}{ }^{+}=450.085 \mathrm{~kg} \\
15.000 X_{4}+d_{4}{ }^{-}-d_{4}{ }^{+}=290.060 \mathrm{~kg} \\
15.000 X_{5}+d_{5}{ }^{-}-d_{5}{ }^{+}=320.075 \mathrm{~kg} \\
\text { Rp. } 2.528 .708 X_{6}+R p .3 .381 .792 X_{7}+R p .4 .320 .792 X_{8} \\
+R p .3 .064 .100 X_{9}+d_{6}{ }^{-}-d_{6}{ }^{+}=R p .328 .560 .500
\end{array}\right\}
$$

\subsection{Penyelesaian Goal Programming Menggunakan Aplikasi QM For Windows}

\subsubsection{Kendala Tujuan 1 (Truk Berkapasitas Muatan 5 Ton)}

Dari hasil penyelesaian Goal Programming diperoleh nilai $X_{1}, X_{2}, X_{3}, X_{4}$ dan $X_{5}$ yaitu sebagai berikut:

$$
\begin{array}{lcl}
X_{1}=6,85 & \text { Solusi ini menghasilkan nilai non-integer, } & X_{1}=6 \text { atau } X_{1}=7 \\
X_{2}=80,02 & \text { sehingga digunakan metode integer } & X_{2}=80 \text { atau } X_{2}=81 \\
X_{3}=90,02 & \text { untuk menghasilkan nilai integer optimal. } & X_{3}=90 \text { atau } X_{3}=91 \\
X_{4}=58,01 & \text { Nilai integer } X_{1}, X_{2}, X_{3}, X_{4} \text { dan } X_{5} \text { adalah: } & X_{4}=58 \text { atau } X_{4}=59 \\
X_{5}=64,02 & & X_{5}=64 \text { atau } X_{5}=65
\end{array}
$$

Untuk biaya yang minimum berdasarkan jumlah kendaraan optimal, maka nilai yang digunakan adalah $X_{2}=80, X_{3}=90, X_{4}=58, X_{5}=64$ sehingga didapatkan nilai $d_{6}{ }^{-}=9.346 .644$.

\subsubsection{Kendala Tujuan 2 (Truk Berkapasitas Muatan 10 Ton)}

Dari hasil penyelesaian Goal Programming diperoleh nilai $X_{1}, X_{2}, X_{3}, X_{4}$ dan $X_{5}$ yaitu sebagai berikut:

$X_{1}=6,85$ Solusi ini menghasilkan nilai non-integer, $\quad X_{1}=6$ atau $X_{1}=7$

$X_{2}=40,01 \quad$ sehingga digunakan metode integer $\quad X_{2}=40$ atau $X_{2}=41$

$X_{3}=45,01$ untuk menghasilkan nilai integer optimal. $\quad X_{3}=45$ atau $X_{3}=46$

$X_{4}=29,01 \quad$ Nilai integer $X_{1}, X_{2}, X_{3}, X_{4}$ dan $X_{5}$ adalah: $\quad X_{4}=29$ atau $X_{4}=30$

$X_{5}=32,01 \quad X_{5}=32$ atau $X_{5}=33$

Untuk biaya yang minimum berdasarkan jumlah kendaraan optimal, maka nilai yang digunakan adalah $X_{2}=40, X_{3}=45, X_{4}=29, X_{5}=33$ sehingga didapatkan nilai $d_{6}{ }^{-}=R p \cdot 7.560 .772$. 
3.4.3. Kendala Tujuan 3 (Truk Berkapasitas Muatan 15 Ton)

Dari hasil penyelesaian Goal Programming diperoleh nilai $X_{1}, X_{2}, X_{3}, X_{4}$ dan $X_{5}$ yaitu sebagai berikut:

$X_{1}=6,85$ Solusi ini menghasilkan nilai non-integer, $\quad X_{1}=6$ atau $X_{1}=7$

$X_{2}=26,67 \quad$ sehingga digunakan metode integer $\quad X_{2}=26$ atau $X_{2}=27$

$X_{3}=30,01$ untuk menghasilkan nilai integer optimal. $\quad X_{3}=30$ atau $X_{3}=31$

$X_{4}=19,34 \quad$ Nilai integer $X_{1}, X_{2}, X_{3}, X_{4}$ dan $X_{5}$ adalah: $\quad X_{4}=19$ atau $X_{4}=20$

$X_{5}=21,34 \quad X_{5}=21$ atau $X_{5}=22$

Untuk biaya yang minimum berdasarkan jumlah kendaraan optimal, maka nilai yang digunakan adalah $X_{2}=27, X_{3}=30, X_{4}=20, X_{5}=22$ sehingga didapatkan nilai $d_{6}{ }^{-}=R p .5 .005 .584$. 


\subsection{Model Kombinasi Kendala Tujuan}

Model ini juga dapat dikombinasikan untuk memperoleh biaya yang lebih minimal lagi. Adapun kombinasi truk yang diperoleh yaitu:

Tabel $7 \quad$ : Kombinasi kapasitas dan jumlah truk

\begin{tabular}{|c|c|c|c|c|c|c|c|}
\hline Kombinasi & $\begin{array}{l}\text { Kapasitas yang } \\
\text { digunakan untuk } \\
\text { Parigi Moutong }\end{array}$ & $\begin{array}{c}\text { Kapasitas yang } \\
\text { digunakan untuk } \\
\text { Palu }\end{array}$ & $\begin{array}{c}\text { Kapasitas yang } \\
\text { digunakan untuk } \\
\text { Manado }\end{array}$ & $\begin{array}{c}\text { Kapasitas yang } \\
\text { digunakan untuk } \\
\text { Poso }\end{array}$ & $\begin{array}{l}\text { Jumlah truk berturut- } \\
\text { turut (Parigi } \\
\text { Moutong, Palu, } \\
\text { Manado, Poso) }\end{array}$ & $\begin{array}{c}\text { Jumlah biaya } \\
\text { distribusi }\end{array}$ & $\begin{array}{l}\text { Penghematan } \\
\text { yang dihasilkan }\end{array}$ \\
\hline 1 & 5 Ton & 5 Ton & 5 Ton & 5 Ton & $80,90,58,64$ & Rp. 319.213.856 & Rp. 9.346.644 \\
\hline 2 & 5Ton & 5 Ton & 5 Ton & 10 Ton & $80,90,58,33$ & Rp. 327.771 .656 & Rp. 788.844 \\
\hline 3 & 5 Ton & 5 Ton & 5 Ton & 15 Ton & $80,90,58,22$ & Rp. 330.944.056 & -Rp. 2.383.556 \\
\hline 4 & 5 Ton & 5 Ton & 10 Ton & 5 Ton & $80,90,29,64$ & Rp. 291.133.388 & Rp. 37.427.112 \\
\hline 5 & 5 Ton & 5 Ton & 10 Ton & 10 Ton & $80,90,29,33$ & Rp. 299.691.188 & Rp. 28.869.312 \\
\hline 6 & 5 Ton & 5 Ton & 10 Ton & 15 Ton & $80,90,29,22$ & Rp. 302.863 .588 & Rp. 25.696.912 \\
\hline 7 & 5 Ton & 5 Ton & 15 Ton & 5 Ton & $80,90,20,64$ & Rp. 284.653.760 & Rp. 43.906 .740 \\
\hline 8 & 5 Ton & 5 Ton & 15 Ton & 10 Ton & $80,90,20,33$ & Rp. 293.211.560 & Rp. 35.348 .940 \\
\hline 9 & 5 Ton & 5 Ton & 15 Ton & 15 Ton & $80,90,20,22$ & Rp.296.383.960 & Rp. 32.176 .540 \\
\hline 11 & 5 Ton & 10 Ton & 5 Ton & 10 Ton & $80,45,58,33$ & Rp. 337.928.516 & -Rp. 9.368 .016 \\
\hline 12 & 5 Ton & 10 Ton & 5 Ton & 15 Ton & $80,45,58,22$ & Rp. 341.100 .916 & -Rp. 12.540 .416 \\
\hline 13 & 5 Ton & 10 Ton & 10 Ton & 5 Ton & $80,45,29,64$ & Rp. 301.290 .248 & Rp. 27.270.252 \\
\hline 14 & 5 Ton & 10 Ton & 10 Ton & 10 Ton & $80,45,29,33$ & Rp.309.848.048 & Rp. 18.712.452 \\
\hline 15 & 5 Ton & 10 Ton & 10 Ton & 15 Ton & $80,45,29,22$ & Rp. 313.020.448 & Rp. 15.540.052 \\
\hline 16 & 5 Ton & 10 Ton & 15 Ton & 5 Ton & $80,45,20,64$ & Rp. 294.810.620 & Rp. 33.749 .880 \\
\hline 17 & 5 Ton & 10 Ton & 15 Ton & 10 Ton & $80,45,20,33$ & Rp. 303.368 .420 & Rp. 25.192.080 \\
\hline 18 & 5 Ton & 10 Ton & 15 Ton & 15 Ton & $80,45,20,22$ & Rp. 306.540 .820 & Rp. 22.019.680 \\
\hline 19 & 5 Ton & 15 Ton & 5 Ton & 5 Ton & $80,30,58,64$ & Rp. 333.206.336 & -Rp. 4.645 .836 \\
\hline 20 & 5 Ton & 15 Ton & 5 Ton & 10 Ton & $80,30,58,33$ & Rp. 341.764 .136 & -Rp. 13.203 .636 \\
\hline
\end{tabular}




\subsection{Pembahasan}

Menurut Kiki. W (2009), dalam Arif, 2012, variabel deviasi atau jarak antara merupakan perbedaan yang khusus membedakan antara Linier Programming dan Goal Programming. Variabel deviasi mempunyai fungsi sebagai penampung terhadap tujuantujuan yang dikehendaki yang dibedakan menjadi dua bagian yaitu deviasi positif $\left(d^{+}\right)$untuk menampung deviasi yang berada di atas tujuan yang dikehendaki, maka $d^{+}$akan selalu berkoefisien -1 pada setiap kendala tujuan dan deviasi negatif $\left(d^{-}\right)$untuk menampung deviasi yang berada di bawah tujuan yang dikehendaki, maka $d^{+}$akan selalu berkoefisien +1 pada setiap kendala tujuan. Dalam perumusan $G P$ dinyatakan faktor prioritas tersebut sebagai $P_{i}$ (untuk $i=1,2, \ldots, m$ ). Faktor-faktor prioritas tersebut memiliki hubungan sebagai berikut: $P_{i}>$ $P_{2}>P_{i+1}$ Model umum dari Goal Programming adalah: Minimumkan: $Z=\sum_{i=1}^{m} P_{i}\left(d_{i}^{+}+d_{i}^{-}\right)$

Berdasarkan jumlah truk optimal, untuk pendistribusian beras di Parigi Moutong, Palu, Manado, dan Poso menggunakan truk berkapasitas 5 ton, maka diperoleh biaya distribusi optimal yaitu sebesar Rp. 319.213.856 dimana biaya distribusi sebelumnya yaitu sebesar Rp. 328.560.500, maka $d_{6}{ }^{-}=$Rp. 9.346.644 atau biaya distribusi dapat dihemat sebesar Rp. 9.346.644. Sedangkan dengan menggunakan truk berkapasitas 10 ton, maka biaya distribusi optimalnya yaitu sebesar Rp. 320.999.728, diperoleh $d_{6}{ }^{-}=$Rp. 7.560 .772 atau biaya distribusi dapat dihemat sebesar Rp. 7.560.772. Begitupula halnya dengan menggunakan truk berkapasitas 15 ton. Biaya distribusi optimal yang diperoleh adalah Rp. 323.554.916, sehingga diperoleh $d_{6}{ }^{-}=$Rp. 5.005.584 atau biaya distribusi dapat dihemat sebesar Rp. 5.005.584.

Namun setelah dilakukan kombinasi-kombinasi jumlah truk optimal untuk menyalurkan beras di Parigi Moutong, Palu, Manado, dan Poso maka diperoleh biaya distribusi yang jauh lebih optimal yaitu sebesar Rp. 293.211.560 dimana biaya distribusi sebelumnya yaitu Rp. 328.560.500, maka biaya distribusi dapat dihemat sebesar Rp. 35.348 .940 perbulannya menggunakan 80 kali distribusi perbulan untuk Parigi Moutong dengan kapasitas muatan 5 ton , 90 kali distribusi perbulan untuk Palu dengan kapasitas muatan 5 ton, 20 kali distribusi perbulan untuk Manado dengan kapasitas muatan 15 ton, dan 33 kali distribusi perbulan untuk Poso dengan kapasitas muatan 10 ton. Selain penghematan biaya distribusi, kombinasi ini juga lebih menguntungkan dalam segi waktu karena penggunaan truk yang tidak banyak.

\section{KESIMPULAN}


Berdasarkan penelitian dan uraian-uraian pada bab-bab sebelumnya, maka dapat disimpulkan bahwa:

1. Persediaan maksimal beras berdasarkan kapasitas gudang dapat memenuhi 6 bulan penyaluran beras yaitu sebesar $8.761 .890 \mathrm{~kg}$ dengan kapasitas gudang $10.000 .000 \mathrm{~kg}$ dimana persediaan sebelumnya sebanyak $4.380 .000 \mathrm{~kg}$ selama 3 bulan.

2. Biaya distribusi optimal adalah Rp.293.211.560 dimana biaya distribusi sebelumnya Rp.328.560.500 sehingga dapat menghemat sebesar Rp.35.348.940

3. Agar pendistribusian beras dapat optimal di Parigi Moutong maka membutuhkan 80 kali pendistribusian menggunakan 1 unit truk berkapasitas 5 ton dengan jumlah yang harus didistribusikan yaitu $400.095 \mathrm{~kg}$ per bulan, 90 kali menggunakan 3 unit truk 5 ton ke Palu dengan jumlah $450.085 \mathrm{~kg}$ per bulan, 20 kali menggunakan 3 unit truk 15 ton ke Manado dengan jumlah $290.060 \mathrm{~kg}$ per bulan, dan 33 kali distribusi menggunakan 2 unit truk berkapasitas 10 ton ke wilayah Poso dengan jumlah yang harus didistribusikan yaitu 320.075 kg per bulan.

\section{DAFTAR PUSTAKA}

[1]. Arif, M., 2012, Model Optimasi Persediaan Bahan Bakar Minyak (BBM) pada pertamina UPMS VII Depot Donggala dengan Menggunakan Metode Goal Programming, Fakultas MIPA Universitas Tadulako, Palu.

[2]. Elikson, D., 2013, Penerapan Metode Goal Programming Untuk Mengoptimalkan Produksi Teh (studi kasus PT. Perkebunan Nusantara IV-Pabrik Teh Bah Butung), Fakultas MIPA Universitas Sumatra Utara, Medan.

[3]. Vinsensia. D, 2009, Studi Tentang Goal Programming Dengan Pendekatan Optimasi Robust, Fakultas MIPA Universitas Sumatra Utara, Medan.

[4]. Wikipedia, 2014, Pengertian Beras. www.WikipediaBahasalndonesia.com, diakses 28 Januari 2015. 